\title{
Significados de Violência Familiar para Idosos no Contexto da Atenção Primária
}

\author{
Ana Claudia Wanderbroocke ${ }^{1}$ \\ Universidade Tuiuti do Paraná \\ Carmen Moré \\ Universidade Federal de Santa Catarina
}

\begin{abstract}
RESUMO - A pesquisa analisou os significados da violência familiar na perspectiva de idosos usuários de uma Unidade Básica de Saúde. Trata-se de um estudo qualitativo, ancorado na Teoria Fundamentada Empiricamente, no qual participaram nove idosos, identificados por profissionais da saúde como vítimas de violência familiar. Os dados oriundos das entrevistas semiestruturadas evidenciaram que o significado de violência familiar contra o idoso está associado a comportamentos de familiares que geram: privação de autonomia, desrespeito por parte dos netos, abandono ou negligência. Alguns tipos de violência não foram reconhecidos pelos participantes em seus próprios relacionamentos com familiares, uma vez que o significado mostrou-se alicerçado na ideia da violência que ocorre "no outro idoso", o frágil e dependente, condição com a qual não se identificaram.
\end{abstract}

Palavras-chaves: Idoso; violência na família; saúde; atenção primária.

\section{Meanings of Family Violence for Elderly People in a Primary Care Context}

\begin{abstract}
In this study the meanings of family violence from the perspective of elderly users of a primary care health unit were analyzed. In this qualitative study, based on grounded theory, nine seniors participated who were identified by health professionals as victims of family violence. Data from semi-structured interviews revealed that the meaning of family violence against the elderly is associated with family behaviors that generate: deprivation of autonomy, disrespect by their grandchildren, abandonment or neglect. Some types of violence were not recognized by participants in their own family relationships, since for them the meaning of violence is something that occurs "with other elderly people", the frail and dependent, persons with which they did not identify themselves.
\end{abstract}

Keywords: Elderly; family violence; health; primary care.

Encontrar um consenso sobre o que vem a ser violência é um grande desafio para as ciências uma vez que ao longo do tempo os significados associados à palavra são construídos e reconstruídos socialmente, com múltiplas perspectivas de análise e de acordo com os contextos sócio-histórico-culturais particulares. O campo de estudo da violência se depara constantemente com as ambiguidades decorrentes desse fenômeno, em função das múltiplas significações que adquire, principalmente, quando se trata de analisá-lo na perspectiva das relações interpessoais. A violência, nesse contexto, é facilmente reconhecida e condenada quando se expressa de forma extrema, mas as violências sutis tendem a permanecer na invisibilidade, e quando o agressor é uma pessoa desconhecida ou distante, o ato é mais facilmente reconhecido do que aquele praticado por uma pessoa das relações próximas. Nesse mesmo sentido, a violência está associada à ambivalência humana na medida em que todas as pessoas trazem em si o potencial para amar e odiar, construir e destruir, pois dosar sentimentos, ações e limites, é um desafio constante nas relações interpessoais.

1 Endereço para correspondência: Rua Sydney Rangel Santos, 238 Curitiba-PR, CEP: 82010-330.E-mail: anawdb@gmail.com.
A família é um dos principais contextos em que a ambivalência nas relações se manifesta, tendo em vista que oferece os primeiros vínculos afetivos e a possibilidade de crescimento de capacidades, potenciais e habilidades necessárias para a autonomia, mas paradoxalmente também é um lugar onde ocorrem sofrimentos e violências. Por essa razão, a família vem se constituindo foco de pesquisas (Fuster, 2002; Minayo, 2003; Ravazzola, 2005) diante do desafio de se compreender e combater principalmente os maus-tratos contra crianças, adolescentes, mulheres e idosos.

Especificamente, no que diz respeito à temática da violência contra o idoso, estudos demonstram que a maior parte das violências sofridas pelos mesmos ocorre nos lares, sendo os principais agressores os filhos homens, noras, genros e cônjuges, havendo forte associação com o uso de álcool e drogas, relação de dependência financeira entre pais e filhos, história de violência na família, sofrimento mental e psiquiátrico, entre outros (Collins, 2006; Minayo, 2007). Apesar da certeza de sua ocorrência, levantar a extensão do problema é um grande desafio para pesquisadores do Brasil e do mundo face às diferentes conceituações de violência empregadas nos estudos, uso de diferentes metodologias e maneiras de acessar os idosos. Cooper, Selwood e Livings- 
tone (2008) em artigo de revisão sistemática da prevalência de violência contra idosos na população mundial identificaram variação de 3,2 a 27,5\%. Da mesma forma, Espíndola e Blay (2007) encontraram pesquisas indicando coeficiente de abuso físico entre 1,2\% na Holanda e 18\% na Finlândia. No Brasil, Moraes, Apratto Júnior e Reichenheim (2008) levantaram a prevalência de violência física contra o idoso no domicílio, em uma população de baixa-renda assistida pelo Programa de Saúde da Família em Niterói, que variou entre $10,1 \%$ (qualquer forma) e 6,3\% (grave). Os autores ponderam que o índice por eles obtido foi bem maior que em outros países, porém similar ao único estudo brasileiro até o momento em que realizaram a pesquisa (Melo, Cunha, \& Falbo Neto, 2006).

No Brasil, apesar dos avanços conseguidos nas políticas públicas voltadas para o enfrentamento da violência contra os idosos, muito ainda precisa ser feito para implementá-las em sua totalidade. O contexto da atenção primária à saúde tem especial importância nesse processo, pois proporciona acesso privilegiado à população e dá aos profissionais possibilidade de atuar na promoção de saúde e encaminhamento aos agravos detectados. Porém, lidar com situações que envolvem violência contra o idoso exige preparo profissional, pois, pesquisadores mostram que os idosos, vítimas de violência familiar, vivem em isolamento, encontram dificuldade em revelar os abusos sofridos, por vergonha ou medo de retaliações dos agressores. Portanto, a maior parte dos maus-tratos que acontece nas famílias se mantém, normalmente, em segredo (Espíndola \& Blay, 2007; Fuster, 2002) e em geral, não chegam aos serviços de saúde, permanecendo naturalizados no cotidiano das relações familiares, nas formas de negligência social e das políticas públicas (Minayo, 2003).

O fato de os idosos não buscarem ajuda ou segredarem as violências sofridas também pode estar relacionado aos significados construídos acerca do problema, uma vez que se parte do pressuposto de que a maneira como as pessoas constroem significados acerca da realidade em que vivem direciona a forma de enfrentar as dificuldades e, de agir no sentido de buscar alternativas para lidar com os problemas. Entende-se que os significados envolvem pensamentos derivados dos processos linguísticos e conversacionais que caracterizam a realidade percebida e construída socialmente pelos indivíduos (McNamee \& Gergen, 1998).

Como base no apresentado, pretende-se analisar os significados construídos sobre a violência familiar por idosos usuários de uma Unidade Básica de Saúde (UBS). Esta pesquisa visa contribuir para a reflexão sobre os valores, hábitos e crenças que estão presentes nas relações interpessoais e que levam à construção de significados em torno da violência familiar contra idosos. Trazer à tona a diversidade de significados atribuídos à violência familiar gera subsídios para orientar novos diálogos entre idosos e profissionais da saúde, sensibilizando-os para a escuta das demandas. Contribui também para o estabelecimento de novas estratégias para o manejo desses casos desde a perspectiva de uma clínica ampliada, onde o cuidado integral e o protagonismo de todos os envolvidos são eixos centrais, conforme prerrogativa da Política Nacional de Humanização (Ministério da Saúde, 2004).

\section{Método}

\section{Participantes}

A participação dos idosos ocorreu mediante o cumprimento dos seguintes critérios: (a) ter 60 anos de idade ou mais, (b) apresentar integridade física e cognitiva suficientes para compreender e responder à entrevista, (c) ser usuário da UBS onde a pesquisa foi realizada há pelo menos 2 anos, e (d) ter sido identificado, por pelo menos um dos profissionais de saúde da UBS em questão, como vítima de violência familiar. O último critério foi assim estabelecido por se entender que a vivência da situação pode estimular o processo de construção de significados sobre o tema, e como não havia na UBS nenhum registro específico sobre a ocorrência de casos que pudesse orientar as pesquisadoras na busca dos participantes, optou-se por seguir a indicação dos profissionais.

Participaram nove idosos, dos quais oito eram mulheres e um era homem, com idades entre 62 e 86 anos e média de 71 anos. Em relação ao estado civil, quatro eram separados, três viúvos, um casado e um vivia em união estável após ter se separado. Seis participantes referiram ser católicos e os outros três posicionaram-se como espírita, protestante e evangélico, respectivamente. Quanto a escolaridade, quatro participantes possuíam o ensino fundamental incompleto, um o ensino médio incompleto, um o ensino médio completo, um superior incompleto e dois superior completo. Quanto a moradia, um morava sozinho, quatro moravam com apenas um filho, dois com o cônjuge/companheira, um com filho e nora, um com filho, neta e bisneto.

\section{Instrumento}

A participação dos idosos se deu por meio de entrevistas semiestruturadas. As entrevistas foram guiadas por um roteiro composto de itens para o levantamento de dados sociodemográficos e de perguntas pré-estabelecidas a partir dos objetivos e da literatura pertinente à pesquisa. $\mathrm{O}$ roteiro foi cumprido na íntegra, porém com abertura para a flexibilização da sequência, uma vez que seguiu o discurso do participante e da dinâmica da entrevista. O roteiro contemplava duas possibilidades para a sequência da entrevista, dependendo se o entrevistado assumia ter ou não sofrido violência familiar. Nos casos em que os idosos consideravam viver ou ter vivido situações de violência, buscava-se conhecer a situação vivenciada, as consequências da violência para a vida dos idosos, e nos casos em que o idoso não reconhecia a situação vivenciada como envolvendo violência, buscava-se o significado da violência contra idosos de forma ampla.

\section{Procedimento}

Para dialogar com idosos sobre experiências acerca da violência familiar, levou-se em consideração as especificidades do tema. Considerou-se o cuidado ético para garantir a liberdade e a concordância em tornar-se um participante, antes da realização da entrevista, expondo o tema e a média 
de tempo que o entrevistado deveria dispor, para que assim, pudesse decidir e organizar suas atividades pessoais.

$\mathrm{Na}$ fase inicial da entrevista, disponibilizou-se um tempo para introdução do assunto em discussão e buscou-se igualmente, uma acomodação mútua à situação de entrevista, facilitando o rapport, que para a psicologia clínica significa o estabelecimento de confiança e cooperação em uma relação. Estruturou-se o roteiro de entrevista para alcançar os objetivos da pesquisa, mas seguindo a ordem dos temas mais gerais aos mais específicos, ou seja, aqueles em que se buscavam os sentimentos e experiências pessoais do entrevistado em relação à violência familiar contra idosos.

Foi realizada uma entrevista com cada idoso e decidiu-se o número de participantes em função da saturação de dados (Strauss \& Corbin, 2008), obtida na entrevista com o sexto participante, quando se observou regularidades nas informações e reincidência temática referentes aos objetivos do presente estudo. Realizaram-se 10 entrevistas a fim de confirmar a recorrência dos dados obtidos. Contudo, uma das entrevistas foi descartada pelo fato de o idoso demonstrar sinais de declínio cognitivo que comprometeram o desenrolar da mesma. Assim, computaram-se os dados de nove entrevistas com idosos para a análise.

O trabalho de campo teve início após a aprovação do projeto pelo Comitê de Ética em Pesquisa da Universidade Federal de Santa Catarina e da Secretaria Municipal de Saúde do município onde a pesquisa foi realizada. Todo o processo de pesquisa atendeu às normas da Resolução 196/96 do Conselho Nacional de Saúde, que correspondem às exigências referentes à ética nas pesquisas com seres humanos.

\section{Análise dos Dados}

Para a análise dos dados foi utilizada a Grounded Theory (Teoria Fundamentada Empiricamente), proposta por Strauss e Corbin (2008), que permitiu trabalhar, comparar, integrar e categorizar os dados obtidos. Concluída a coleta dos dados, foram realizadas sucessivas leituras das entrevistas, seguido do processo de desmembramento, exame, comparações e categorização dos dados, etapa denominada de codificação aberta, permitindo a identificação dos aspectos em comum, bem como características diferenciais e pontos inéditos entre todos os dados obtidos. A partir desse ponto, emergiram pontos nucleares que se mantiveram na diversidade e na complexidade dos dados recolhidos e que guiaram a construção das categorias principais, subcategorias e seus respectivos elementos de análise, etapa denominada codificação axial. Finalmente, o processo de codificação seletiva permitiu integrar e refinar o conjunto de dados obtidos proporcionando uma compreensão integrada do fenômeno central.

\section{Resultados}

Foi possível visualizar, e caracterizar, nas entrevistas realizadas, situações de violência sofrida pelos participantes tomando como base a definição de violência contra o idoso proposta pela Rede Internacional para Prevenção dos Maus tratos contra Idosos, qual seja, "ato único, repetido ou falta de ação que ocorre no contexto de uma relação na qual há uma expectativa de confiança e que causa danos ou perturbações à pessoa idosa" (Minayo, 2007, p. 200). De acordo com os tipos de violência definidas por Faleiros (2007), a violência psicológica foi a mais frequente, encontrada em seis casos, seguida da violência física em quatro casos, violência financeira em três casos e um caso de negligência e outro de violência sexual. Com exceção de três casos, houve associação entre dois tipos de abusos sofridos.

Durante a realização das entrevistas, seis participantes assumiram ter sofrido violência familiar, sendo que um deles assumiu somente ao final da entrevista e outros três negaram a experiência de qualquer tipo de violência. Uma das entrevistadas identificou em suas experiências um tipo de violência e não outro, que ficou evidente para as pesquisadoras em seu relato. As razões para que parte dos idosos não tenha feito referência às violências sofridas serão analisadas no decorrer deste estudo.

Quanto ao tempo de ocorrência da violência, para quatro, ela acontecera no passado e afirmaram já ter superado o problema. Nos outros cinco casos a violência ainda ocorria quando da realização da entrevista. Os agressores indicados ou percebidos eram filhos, em cinco casos; noras, em três casos; maridos, em dois casos; sobrinho, em um caso; em cinco situações, identificaram-se mais de um familiar. A partir dos dados contidos nas narrativas dos idosos foram estabelecidas cinco categorias, cada uma delas com suas respectivas subcategorias e elementos de análise, possibilitando uma leitura transversal dos dados, como também uma análise em profundidade do conteúdo emergente nas entrevistas. Todos os dados gravitaram em torno do fenômeno central da pesquisa, qual seja, os significados construídos por idosos usuários de uma UBS acerca da violência familiar.

A categoria 'significados atribuídos à violência e à violência familiar contra os idosos' foi selecionada para responder ao objetivo do presente artigo e congrega as subcategorias: (a) percepção de diferentes tipos de violências, (b) descrição de comportamentos de familiares em relação ao idoso e (c) avaliação da experiência vivenciada na própria família.

\section{Discussão}

A categoria significados atribuídos à violência e à violência familiar contra o idoso abordou o processo de formação de imagens, ideias e pensamentos sobre o tema violência de forma ampla e da violência familiar contra o idoso em particular, que incluiu considerações sobre acontecimentos sociais e análise de experiências pessoais. A primeira subcategoria, percepção de diferentes tipos de violência, assinalou como os idosos explicaram a sua compreensão da palavra violência.

A violência física foi mencionada por todos os participantes que a ilustraram com diversos exemplos e, apesar de no início definirem a violência como agressão física, frequentemente externavam clareza em relação à existência de outros tipos de agressão. A violência física apareceu como ponto de partida para esclarecerem o significado de violência, porém a violência verbal ou psicológica foi apontada por oito participantes como tanto ou mais danosa. 
Ah, a violência, tem a de forma verbal, não seria necessariamente de forma física. Às vezes o próprio familiar não respeita, não trata como o idoso deveria ser tratado. É violência, é tudo aquilo que agride a pessoa, que leva a pessoa a ficar triste, ficar chateada com isso. (Opala)

Exemplos de violência comunitária, como o aumento da criminalidade e de assaltos nas cidades, o desrespeito dos mais jovens em relação aos idosos nos transportes coletivos e a violência no trânsito, também foram utilizados por quatro entrevistados como meio de significar a palavra violência, como no seguinte depoimento.

\begin{abstract}
Ah, não tem nem como explicar, né. Porque a violência tá tão variada que você não sabe como. Você sai na porta ... Meu marido anda devagar, se arrastando, não é por causa da doença, ele anda se arrastando porque ele foi assaltado três vezes. $E$ uma vez ele foi assaltado aqui na frente da porta. Ele vinha chegando da padaria e eles não sabiam que ele morava aqui. Dois rapazes, um pegou ele assim pelas pernas e o outro foi examinar. 'Não se mexa, não grite, não reclame que nada te acontece'. (Esmeralda)
\end{abstract}

Percebe-se que o entendimento inicial associado à palavra violência diz respeito às ações que causam primeiramente, dano físico ao outro, e depois, dano psicológico. Entretanto, as falas envolvendo outras formas de manifestação da violência, como a sexual e a comunitária remeteram implicitamente, à imagem de um dano corporal. A violência física também apareceu como contraponto para a ampliação do significado original, ou seja, empregaram essa denominação para esclarecer que ela não causa somente danos físicos, mas também, psicológicos ou em outras áreas. Dessa forma, o significado de violência, mesmo se relacionando a diferentes manifestações, ancorou-se nas agressões física e psicológica.

Pesquisadores que averiguaram a concepção de violência entre idosos usuários do sistema básico de saúde como Silva, Oliveira, Joventino e Moraes (2008), encontraram em referências iniciais as formas de violência estrutural, institucional e/ou comunitária, com presença irrelevante de questões familiares. Diferentemente, na presente pesquisa, entre os exemplos disponibilizados pelos idosos, constaram violências sociais, comunitárias e violência familiar e abordaram aspectos envolvendo violência estrutural e institucional. Essas diferenças podem indicar que a metodologia utilizada e os objetivos estão provavelmente implicados, já que no estudo anteriormente citado foi utilizado grupos focais. Essa escolha possivelmente dificultou ou atrasou comentários de questões pessoais. Outro dificultador é que os pesquisadores buscavam a concepção de violência contra idosos de forma mais ampla, enquanto o presente estudo enfoca a violência familiar. Outra hipótese a se considerar sobre essa diferença é que no decorrer das entrevistas desta pesquisa, parte dos idosos admitiu ser vítima de violência familiar.

A segunda subcategoria, 'descrição de comportamentos de familiares em relação ao idoso', descreveu como os participantes percebem as agressões contra os idosos existentes nas relações familiares. A agressão física foi novamente a forma de violência mais indicada pelos participantes, geralmente fazendo referência ao idoso fragilizado física e mentalmente, como nos exemplos a seguir.

Isso a gente está vendo direto na televisão. Quantas vezes aparece, as pessoas estão filmando e as pessoas batem no sujeito com Alzheimer, Parkinson, que nem entende mais nada, gente com 80, 90 anos, eles batem, dão soco, já viu na televisão? Isso é um absurdo. (Topázio)

Ao comentar sobre o asilamento da pessoa idosa, o depoimento a seguir enfatiza os maus-tratos físicos praticados em certas instituições.

Esses filhos que põem lá em orfanatos, em clínicas particulares, que batem, maltratam, judiam, chegam até morrer, né. Essa parte ai que eu acho que é violência para o idoso e bastante, né. (Pérola)

A agressão verbal foi citada nas entrevistas por meio de diferentes exemplos de maus-tratos verbais dirigidos aos idosos, como o falar de forma ríspida ou expressar conteúdos que abalam psicologicamente o idoso.

Ah, eu acho muito ruim, muito ignorante essa pessoa, porque a pessoa de idade é muito frágil. Como é que vai lutar com uma pessoa, se defender?(...) Às vezes nem entendem se vem uma pessoa assim e fala meio grosso com eles, meio bravos assim, então eles ficam frágeis, eles não sabem o que responder. (Alexandrita)

Os tipos mais recorrentes de violência física e psicológica contra os idosos, indicados pelos participantes, coincidem com os descritos na literatura. As narrativas também evidenciaram que os diferentes tipos não podem ser categorizados isoladamente, pois, geralmente aparecem associados (Faleiros, 2007)

A negligência ou abandono foram apontados por três pessoas como atitudes violentas dos familiares em relação aos idosos e notou-se que os dois termos apareceram indistintamente nas falas dos participantes. Para Minayo (2006), a negligência é caracterizada pela recusa ou omissão dos cuidados necessários aos idosos pelos familiares ou responsáveis institucionais. O abandono, por sua vez, representa a ausência ou deserção dos mesmos, compreendido como uma diferença de grau entre um tipo e outro. Ao mencionar a falta de cuidados, observou-se um certo titubeio ou incerteza inicial, por parte de alguns entrevistados, em apontá-los como uma forma de violência, por configurarem situações sem agressões físicas ou verbais como nos casos anteriormente apontados.

O seguinte entrevistado iniciou seu depoimento falando acerca da violência física a que os idosos dependentes estão sujeitos e na sequência amplia seu discurso apontando o isolamento ou descuido, que pode ser compreendido como uma negligência dos familiares, ao não atenderem a necessidade de atenção que os idosos possuem.

(...) É só quando é problema de gente doente que eles maltratam assim para valer. Quando a pessoa está saudável, não vou dizer que tenha agressão, mas tem o desprezo, né. A pessoa fica num 
canto lá e ninguém dá bola. Isso é o que acontece muito no dia-a-dia, é desprezo, que não deixa de ser uma violência. Não deixa de não ser uma violência ... (Topázio)

A participante a seguir aponta a negligência de um dos filhos de uma amiga sua, que no seu entender, deixa a mãe passar por privações financeiras. Apesar do conteúdo de sua fala corresponder à negligência como um dos tipos de violência contra os idosos, no seu depoimento é nomeada como abandono.

Eu vejo essa minha amiga, não é violência, mas o abandono que ela tem. É viúva, tem dois filhos e um faleceu. Mas esse que é advogado, isso e aquilo, pouco se importa com a mãe. Ele dá uma ajudazinha, não quero dizer que não dá. Mas a ajuda dele é um real. (...) É uma violência. Abandona ela, ela chora 'faz três semanas que não vejo meu filho, que não sei do meu filho', com dez telefones ali na mesa dele. Essa é uma violência muito grande. (Esmeralda)

Três participantes entenderam que a retirada da autonomia é uma forma de violência por parte dos familiares quando não respeitam a capacidade do idoso em gerenciar a própria vida, como ilustrado a seguir no comentário de Esmeralda sobre suas amigas.

Essa outra também tem dois anos menos e essa outra tem a minha idade, mas essa tem a independência dela, tem o dinheiro dela, ela trabalhou, está aposentada, não é fortuna, mas dá pra ela viver. Mas também reclama dos mandões que querem mandar nela, 'todo mundo quer mandar em mim, todo mundo quer que eu faça isso, todo mundo quer que eu faça aquilo, como é que eu vou fazer tudo que os outros querem? Eu tenho que fazer aquilo que eu quero e que eu posso. 'É assim mesmo e cada vez vai ficar pior. (Esmeralda)

A autonomia garante ao idoso a possibilidade de se autogovernar, a liberdade individual, a privacidade e a livre-escolha (Neri, 2001) e é uma condição fundamental para garantir o exercício de funções e a reciprocidade nas relações com os integrantes da rede social. Portanto, faz sentido que o ser privado de exercer a autonomia tenha sido considerado como uma violência contra os idosos.

O desrespeito dos netos surgiu na fala de uma das participantes que denota casos de conflitos intergeracionais.

(...) Então a gente vê netos que não respeitam os avós, não é o meu caso por que eu não tenho netos ainda, mas a gente ouve. Inclusive ontem eu tive uma audiência com a juiza, a respeito do meu filho, e uma das reuniões, lá, foi falado sobre isso, sobre os maus tratos com os avós, com os idosos, eles dizem que tem uma grande incidência de avós que tem procurado o serviço, de violências domésticas, pra pedir ajuda.(Opala)

Santos, Silva, Carvalho e Menezes (2007) confirmam essas ocorrências e ressaltam que os netos despontam como agressores e homicidas de seus avôs. Reafirmam assim, a violência que ocorre nos lares, principalmente, quando os netos dependem deles financeiramente.
Os comportamentos de familiares descritos pelos participantes como violência contra o idoso, incluíram as agressões físicas e psicológicas, como também o abandono, a negligência, desrespeito pelos netos e o tirar a autonomia dos mais velhos. Esses dados apresentam pequenas variações entre os estudos que levantaram a concepção de violência contra os idosos por pessoas também idosas. Flanders (2006) apontou a negligência psicológica, o abandono e o abuso físico como as violências mais citadas por idosos. Silva e cols. (2008) descreveram como as principais referências dos idosos as formas de violência física e psicológica e conflitos entre idosos e seus netos. Araújo e Lobo Filho (2009) encontraram expressões como abandono, desrespeito, negligência e agressão física entre as explanações de idosos acerca da violência familiar.

Os dados apresentados indicam que os idosos participantes, por se verem como pessoas ativas e participativas, com saúde e independentes, não se percebiam como parte de uma construção social que significa a velhice como fase de dependência e isolamento. Os exemplos descritos ilustram o que foi exposto por Mercadante (2005) quanto às construções sociais acerca do que é ser velho, ou estar na velhice ser carregadas de preconceito e, portanto, a pessoa que envelhece muitas vezes procurar distanciar-se desse estereótipo, colocando o idoso como "o outro", não se identificando ou se incluindo naquilo que tem esse significado. Nesse mesmo sentido, os exemplos de violências sofridas diziam respeito a um "outro idoso", aquele mais frágil e dependente e não àquele que fala, mesmo que posteriormente admitisse ser vítima de algum tipo de maltrato.

Cabe observar que os primeiros elementos de análise da subcategoria por hora discutida repetem a concepção trazida na subcategoria anterior, ou seja, quando convidados a falarem sobre a violência contra o idoso especificamente, os comportamentos descritos iniciam com a ideia central de violência física e psicológica.

De acordo com Gergen (2009), os significados se constroem nas relações sociais e demandam a presença do outro para haver a suplementação dos significados. Dessa maneira, detectou-se na fala dos participantes, referência à discussão com outras pessoas do seu círculo social, de casos de violência física contra idosos dependentes, veiculados em canal de televisão com repercussão local. Esse meio de comunicação intervém nas relações sociais, uma vez que os assuntos abordados nos noticiários são frequentemente debatidos nas conversas entre familiares e conhecidos. Em relação ao tema desta pesquisa, pode-se inferir que a televisão, ao mesmo tempo em que alerta sobre a existência da violência familiar e orienta sobre medidas cabíveis, contribui para reforçar o conceito de violência, associado às agressões físicas contra idosos fragilizados.

Em contrapartida, quando os entrevistados encontraram espaço na conversação, possibilitou-se a ampliação dos significados. Esse fato foi observado em exemplos em que inicialmente, apresentaram novos significados manifestando incerteza quanto à sua credibilidade, mas, após a concordância da entrevistadora, imprimiram um tom de certeza ao enunciado. Gergen (1996) contribui para o entendimento desse fato ao assumir que os significados estão sujeitos à reconstituição contínua através 
da expansão do domínio da suplementação, isto é, os significados mantêm-se como uma realização temporária, sujeitos a acréscimos e alterações concebidos por meio de significações suplementares.

A terceira subcategoria, avaliação da experiência vivenciada na própria família, discutiu o significado da violência familiar contra o idoso a partir do julgamento feito pelo entrevistado das experiências vividas nas próprias relações com seus familiares. Entre os nove entrevistados, seis ao comentarem a situação a avaliaram como violência, como exemplificado no seguinte depoimento:

Sim, eu já sofri agressão, né, da parte deles [filhos], tanto é que eu resolvi me mudar e ficar sozinha pra ter maior liberdade. Eu já tive envolvimento com polícia, tanto é que agora precisei prender o meu próprio filho, solicitar a ajuda da polícia, por que ele chegou drogado, embriagado, quebrou a porta, entrou e tal ... então, a gente passa por essas dificuldades. (Opala)

Um dos participantes negou, ao longo da entrevista, haver qualquer violência na sua família, mas no final, ao encerrar o encontro, comentou:

Ah ... para não dizer que eu achei que isso foi violência, foi o que um sobrinho fez, sou padrinho dele, chegou um dia: 'Tio, me ajuda, podia me avalizar para comprar um carro?' largou tudo para mim pagar. (...) Isso ai é violência. Olha a sacanagem. Teve coisa que eu não paguei, não tinha de onde tirar para pagar. Assinei ... e teve coisa que eu comprei no meu nome para ele, e ele sumiu e largou tudo nas minhas costas. Esses dias mesmo eu acabei de pagar um troço no cartão, fiquei dois anos pagando conta dele. (Topázio)

Ao relatarem suas experiências pessoais de violência familiar, os entrevistados não estabeleceram relação com o fato de serem idosos, o que pode ser relacionado ao dado anteriormente apresentado de o significado da palavra "idoso" os remeterem às pessoas de idade mais avançada, fragilizadas e dependentes, impedindo-os de fazer associação consigo. Outro aspecto relevante, como já vinham lidando com a violência nas relações familiares há anos, a experiência não foi associada à velhice, inclusive duas participantes relataram a separação de seus companheiros agressores por violência conjugal.

Dessa forma é possível compreender porque ao serem questionados sobre a violência familiar contra o idoso não tenham associado às próprias experiências imediatamente, pois ainda não se viam incluídos no assunto em questão. Como pessoas capazes de gerir a própria vida, não se adequavam aos significados atribuídos aos idosos, tampouco a sua experiência familiar na categoria "violência familiar contra o idoso".

A única exceção foi o participante que sofreu um episódio de abuso financeiro já na velhice e narrou o fato da seguinte maneira:

Olha essa do meu sobrinho aí, se eu fosse no Ministério Público, com o código do idoso ele ia se lascar, porque isso ai ... tem um termo jurídico ai ... ele usou de má fé, passou o idoso para trás.(...) (Topázio)
Outras três idosas não avaliaram a situação vivida como violência. Entre elas, uma reconheceu um tipo de violência sofrida e outro não. No primeiro caso, a participante, ao longo da entrevista, demonstrou o seu descontentamento pelo fato de a sobrinha, que morava na casa ao lado, parecer não respeitar o seu desejo de manter objetos e pertences que considerava ainda poderem ser úteis ou que lhe traziam recordações do passado. Comentou que a sobrinha não compreendia e não respeitava seu modo de viver, por isso a entrevistada lutava para manter a sua autonomia. Ao falar sobre o significado de violência comentou sobre os familiares tirarem a autonomia dos idosos, citando exemplos de amigas suas, que passavam por isso. Quando questionada se em alguma situação ou momento sentiu sofrer algum tipo de violência ela negou e esclareceu dizendo que em sua família não existia violência. Fazendo menção à violência física, comentou:

\section{Não, graças a Deus, não. Minha família, minha mãe nos criou sem pai, porque o nosso pai faleceu quando eu tinha um ano $e$ oito meses. Minha mãe criou no duro mesmo, mas criou todos direitinho. Minha mãe nunca bateu nos filhos. Ela falava e os filhos obedeciam porque ela estava falando uma coisa certa. Mamãe não mentia. (Esmeralda)}

Ao ser questionada sobre os acontecimentos do presente e as atuais relações familiares também negou sofrer qualquer tipo de violência e não mencionou o fato de sentir que lhe tiravam a autonomia. Também não fez qualquer referência à insuficiência de cuidados recebidos por parte de familiares, uma vez que ela e o marido sofriam visíveis limitações físicas, o que caracterizaria a situação como negligência familiar, motivo pelo qual seu caso foi sugerido por profissionais da UBS para a presente pesquisa.

A fala a seguir, ilustra o posicionamento de outra entrevistada que ao responder sobre o significado de violência, complementa a frase com o comentário de que o filho a agredia verbalmente, mas no seu entender isso não era violência.

Da parte dele não, eu acho, eu fico sentida e magoada, porque ele não tem respeito por mim, aonde a vida toda eu corri, paguei as contas dele, a vida toda eu paguei conta dele, ele ganhava era só pra comprar livro. (Pérola)

A entrevistadora reformulou o questionamento sobre se essa situação se caracterizava, ou não, como violência. Ela então deixou clara a sua concepção de violência.

Não, aí se ele me agredisse, me batesse seria, pra mim seria
uma violência. Mas quando ele diz esses horrores só falta eu
me deitar e dizer que quero morrer, porque eu fico abalada (...)
Então pra mim, não seria violência, mas seria uma coisa que
me magoa profundamente e me tira dez anos de vida. (Pérola)

A terceira entrevistada que negou ser vítima de violência foi indicada como uma possível participante desta pesquisa por ser responsável financeiramente por uma filha adulta, por uma neta adolescente e por um bisneto recém nascido. No entender da agente comunitária que a encaminhou, tratava-se de um caso de exploração financeira, que poderia ser carac- 
terizado como violência, mas para Turmalina a sua situação de vida tinha outro significado, como sua fala esclarece:

Eu tenho a minha própria vida. Quer dizer, eu me prendo, como eu estava te falando, por causa do neném, porque eu cuido dele de noite. Mas eu faço isso espontaneamente, faço porque eu quero e não porque elas me obriguem. A partir do momento que me obrigassem talvez eu não fizesse. (...) (Turmalina)

Ao discorrer sobre o que entende por violência, exemplificou com a sua relação com a filha, assumindo que havia alguns conflitos entre elas, como segue.

Violência é também quando a pessoa discute, às vezes se você diz uma coisa e a pessoa retruca com outra na mesma altura. Então eu procuro evitar, quando tem esse tipo de violência, vamos dizer. Mas ai é uma coisa assim passageira. Ela também já se arrepende, já vem me pedir coisa. E às vezes eu também digo pra ela que ela deveria procurar um lugar pra morar. Mas o que mais interfere agora é o neném, eu sinto assim que ela tem ciúme da criança. Então ela acha assim 'ah, você não deve fazer isso, porque quem sabe sou eu, eu que sou a avó do neném', é uma questão de ciúmes. (Turmalina)

Segue um pequeno trecho da entrevista onde a entrevistadora indagou a participante sobre quando se pode dizer que há violência nas relações entre familiares, ao que ela responde:

T: Ah, quando bate um no outro, não é assim?

P: Quando chega ao ponto de ser uma agressão física?

T: $\dot{E}$.

P: Se for só verbal, se for só falar coisas um pro outro não?

T: Não, também é violência. Agora, quando é agressão física ai é grave. E como existe! Filho que mata a mãe, um monte de coisas.

Entre as entrevistadas que negaram sofrer violência, Safira vivia em um apartamento com um filho dependente químico que segundo ela, era agressivo quando se encontrava sob efeito de drogas. Safira possuía mais um filho que, influenciado pela esposa, achava que a melhor solução seria a venda do apartamento, assim a afastaria do filho agressor. O filho dependente químico também a pressionava, pois achava que seria uma forma de disporem de algum capital, uma vez que passavam por dificuldades financeiras naquele momento. A possibilidade de venda do apartamento era fonte de angústia para Safira, pois os filhos falavam na venda, mas não onde e como viveriam depois de concretizá-la. Ao ser interrogada sobre sofrer algum tipo de violência, ela admitiu a violência psicológica, mas não fez nenhuma menção à violência financeira.

A partir desses exemplos deduz-se que o significado de violência, ancorado na ideia de agressões físicas e psicológicas, impede que os idosos visualizem outras condições que também poderiam ser caracterizadas como tal. No caso de Pérola, o significado estava restrito à violência física, o que a impediu de nomear sua experiência como violência psicológica.

Nesse sentido, Gergen (1996) afirma que os suplementos atuam tanto para criar como para restringir o significado, ou seja, quando um significado em comum é construído, se restringem as possibilidades de nova significação. Se violência é agressão física e/ou psicológica, os demais fatores capazes de causar danos ou sofrimento às pessoas ficam obscurecidos.

O não reconhecimento da violência como tal, mesmo que as situações vivenciadas sejam geradoras de sofrimento, pode impedir as pessoas de buscarem uma solução ou um enfrentamento mais efetivo. Além de dificultar o enfrentamento, a naturalização dessas situações pode ser a consequência, ou seja, o idoso encontra uma explicação que justifica e dá um sentido para a violência sofrida.

Esses exemplos ilustram também a dificuldade em se objetivar e definir os casos de violência, já que estão em constante construção e significação, tanto pelos indivíduos que a sofrem como pelos membros da sociedade. Nesses casos, as situações vividas pelos idosos foram interpretadas como envolvendo violência por parte de pelo menos um profissional de saúde, mas não pelos idosos, o que levanta o questionamento de como é possível atuar profissionalmente diante dessas situações.

\section{Considerações Finais}

A partir dos dados apresentados pode-se considerar que o significado de violência tanto de forma geral como a violência contra os idosos está alicerçado na ideia de agressões física e psicológica. A partir desses conceitos centrais, o significado se ampliou ao longo das entrevistas, indicando diversos comportamentos de familiares, considerados inaceitáveis e contrários aos valores de família e de suas expectativas, ampliando a significação de violência familiar contra os idosos. Portanto, consideraram violência privar o idoso de sua rotina de vida que lhe confere autonomia, o que denota a importância que atribuem a essa condição. Outro tipo de violência citada foi o desrespeito dos netos, uma vez que a reciprocidade de atenção e cuidados foi por eles valorizada. Da mesma forma, denominaram violência abandonar ou negligenciar o idoso quando se torna frágil e dependente, pois esperam que a família ofereça cuidados quando o idoso se apresenta nessa condição.

Ao pensarem as próprias relações familiares, a opinião de parte dos idosos não coincidiu com a avaliação das pesquisadoras e dos profissionais que os indicaram, ou seja, situações envolvendo negligência, perda de autonomia, abuso psicológico e financeiro não foram identificadas por alguns participantes como violência familiar. Entende-se que essas experiências não foram concebidas como violência por estar o significado de violência, se tomada de forma ampla, ancorado nas agressões físicas e psicológicas e o significado de violência contra o idoso, na ideia de fragilidade e dependência. Nesse sentido, os participantes ao avaliarem as próprias relações familiares, nem sempre identificaram situações de violência por não refletirem os tipos citados de agressão e, uma vez que também não se viam como idosos frágeis e dependentes, não fizeram a aproximação do conceito às vivências pessoais. Da mesma maneira, quando assumiram as violências sofridas não a relacionaram ao fato de serem idosos, por não se verem como tal e porque algumas vezes 
essas violências eram decorrentes da etapa anterior do ciclo de vida e não associadas à etapa da velhice.

Os significados construídos acerca do termo violência contra o idoso especificamente, podem indicar caminhos para se trabalhar com a questão, uma vez que diante de uma construção comum de significados, que adquirem certo consenso entre as pessoas de um determinado contexto social, outros são restringidos ou não são identificados (Gergen, 1996). Isto quer dizer que ao serem propostos trabalhos voltados para idosos vítimas de violência ou serem feitas divulgações na mídia sobra a violência contra os idosos, cabe pensar na grande diversidade de condições em que as pessoas se encontram na velhice e que nem sempre, como os dados desta pesquisa indicaram, se identificam como idosos ou com as questões atribuídas a essa fase no ciclo de vida.

Embora o caminho utilizado nesta pesquisa para acessar idosos vítimas de violência possa apresentar limitações inerentes ao processo de pesquisa, a oportunidade de ouvir a experiência dessas pessoas foi relevante para a reflexão e discussão sobre os significados da violência, e reconhecer que se trata, como se mostrou ao longo deste trabalho, de um fenômeno impreciso, mutante e subjetivo. Com base nos dados apresentados, considera-se fundamental sensibilizar os profissionais da saúde, principalmente os da atenção primária, a reconhecer a fluidez do conceito, uma vez que é necessário que haja contextualização das histórias de vida, o que constitui o primeiro passo para a efetivação das políticas públicas direcionadas ao enfrentamento da violência contra idosos. Esse processo de sensibilização gera condições de maior clareza sobre a violência, o que possibilita incrementar medidas de rastreamento por meio de instrumentos específicos, como também do olhar e da escuta atentos do profissional em relação ao usuário, nos diversos serviços e atividades oferecidos à população.

Considera-se que os dados apresentados contribuem como subsídios para uma melhor compreensão e ampliação da temática abordada. Por sua vez, reconhece-se a sua complexidade, pela diversidade de aspectos que necessariamente precisam convergir para melhor análise da questão. Portanto, novos estudos são necessários para a aproximação e compreensão dos desafios que envolvem lidar com a violência familiar contra idosos. Sugere-se como temas para futuras pesquisas as formas de enfrentamento utilizadas por idosos que sofrem violência familiar e as limitações enfrentadas pelos profissionais que atuam com idosos em manejar casos de violência familiar detectados.

\section{Referências}

Araújo, L. F., \& Lobo Filho, J. G. (2009). Análise psicossocial da violência contra os idosos. Psicologia Reflexão e Crítica, 22(1), 153-160.

Ministério da Saúde (2004). HumanizaSUS: Política Nacional de Humanização: A humanização como eixo organizador de todas as práticas de atenção e gestão em todas as instâncias do SUS. Brasília: Ministério da Saúde.

Collins, K. A. (2006). Elder maltreatment: A review. Archives of Pathology \& Laboratory Medicine, 130, 1290- 1296.
Cooper, C., Selwood, A., \& Livingstone, G. (2008). The prevalence of elder abuse and neglect: A systematic review. Age and Aging, 37, 151-160.

Espíndola, C. R., \& Blay, S. (2007). Prevalência de maus-tratos na terceira idade: Revisão sistemática. Revista de Saúde Pública, 41(2), 301-306.

Faleiros, V. P. (2007). Violência contra a pessoa idosa. Ocorrências, vitimas e agressores. Brasília: Universa.

Flanders, W. B. (2006). Perspectives on elder abuse and neglect in Brazil. Educational Gerontology, 32, 63-72.

Fuster, E. G. (2002). Las víctimas invisibles de la violencia familiar. El extraño iceberg de la violencia doméstica. Buenos Aires: Paidós.

Gergen, K. J. (1996). Realidades y relaciones: Aproximaciones a la construción social. Barcelona: Paidós.

Gergen, K. J. (2009). An invitation to social construction (2nd. ed.). London: Sage.

McNamee, S., \& Gergen, K. J. (1998). A terapia como construção social. Porto Alegre: Artes Médicas.

Melo, V. L., Cunha, J. O. C., \& Falbo Neto, G. H. (2006). Maustratos contra idosos no município de Camaragibe, Pernambuco [Suplemento 1]. Revista Brasileira de Saúde Materno Infantil, $6,543-548$.

Mercadante, E. F. (2005). Velhice: Uma questão complexa. In B. Corte, E. F. Mercadante, \& I. Arcuri, (Eds.), Velhice, envelhecimento e complex(idade) (pp. 23-34). São Paulo: Vetor.

Minayo, M. C. S. (2003). Violência contra idosos: Relevância para um velho problema. Cadernos de Saúde Pública, 19(3), 783-791.

Minayo, M. C. S. (2006). Violência e saúde. Rio de Janeiro: Editora Fiocruz.

Minayo, M. C. S. (2007). Violência contra a pessoa idosa: o direito pelo avesso. In M. Papaléu Netto (Ed.), Tratado de gerontologia (2a . ed., pp. 199-210). São Paulo: Atheneu.

Moraes, C. L., Apratto Jr, P. C., \& Reichenheim, M. E. (2008). Rompendo o silêncio e suas barreiras: Um inquérito domiciliar sobre a violência doméstica contra idosos em área de abrangência do Programa Médico de Família de Niterói, Rio de Janeiro, Brasil. Cadernos de Saúde Pública, 24(10), 2289-2300.

Neri, A. L. (2001). Palavras-chave em gerontologia. Campinas: Alínea.

Ravazzola, M. C. (2005). Histórias infames: Los malostratos en las relaciones. Buenos Aires: Paidós.

Santos, A. C. P., Silva, C. A., Carvalho, L. S., \& Menezes, M. R. (2007). A construção da violência contra idosos. Revista Brasileira de Geriatria e Gerontologia, 10(1), 129-140.

Silva, M. J., Oliveira, T. M., Joventino, E. S., \& Moraes, G. L. A. (2008). A violência na vida cotidiana do idoso: Um olhar de quem a vivencia. Revista Eletrônica de Enfermagem, 10(1), 124-136. Retrieved from http://www.fen.ufg.br/revista/ v10/ n1/ pdf/v10n1a11.pdf

Strauss, A. \& Corbin, J. (2008). Pesquisa qualitativa. Técnicas e procedimentos para o desenvolvimento de teoria fundamentada ( $2^{\mathrm{a}}$. ed.). Porto Alegre: Artmed.

Recebido em 07.02.2011

Primeira decisão editorial em 28.06.2011

Versão final em 14.07.2011

Aceito em 22.08.2011 